\title{
The first report of molecular characterized BRD4-NUT carcinoma in Brazil: a case report
}

\author{
Leandro J. C. Oliveira ${ }^{\text {* }}$, Aline B. L. Gongora', Marcela T. Latancia², Felipe G. Barbosa ${ }^{3}$, João Vitor A. M. Gregorio ${ }^{1,4}$, \\ Leonardo A. Testagrossa ${ }^{5}$, Mariane T. Amano ${ }^{2}$ and Olavo Feher ${ }^{1,4}$
}

\begin{abstract}
Background: NUT midline carcinoma is a rare and aggressive subset of squamous cell carcinoma, which is characterized by the translocation of nuclear protein in testis gene that is mostly fused with bromodomain and extraterminal family proteins. We describe here the first Brazilian case of NUT midline carcinoma with BRD4-NUT fusion detected in a nextgeneration sequencing panel and we present the clinical evolution of this patient.

Case presentation: A 42-year-old Caucasian man was diagnosed with poorly differentiated squamous cell carcinoma of the left maxillary sinus, with negative in situ hybridization for Epstein-Barr encoding region and human papillomavirus genotyping. He received induction therapy, chemoradiotherapy with weekly systemic chemotherapy, and, concurrently, weekly intra-arterial chemotherapy. New imaging evaluation, 1 month after the end of the last treatment, revealed a good partial response in the primary lesion. However, positron emission tomography-computed tomography showed multiple suspicious lesions in his bones and lungs, which were histologically confirmed. He died exactly 2 months after metastatic disease was diagnosed.

Conclusions: NUT midline carcinoma is usually very aggressive. Currently, there is no standard of care for treatment of NUT midline carcinoma. The definitive diagnosis must be by demonstration of NUTM1 rearrangement. Immunohistochemical staining of greater than $50 \%$ of tumor nuclei on formalin-fixed paraffin-embedded tissue using the monoclonal rabbit antibody to NUT (clone C52B1), has a specificity of 100\%, and sensitivity of $87 \%$ for the diagnosis of NUT midline carcinoma. Our case is the first Brazilian case of NUT midline carcinoma with BRD4-NUT fusion.
\end{abstract}

Keywords: NUT midline carcinoma, Poorly differentiated squamous cell carcinoma, Molecular pathology, Targeted therapy

\section{Background}

NUT midline carcinoma (NMC) is a rare and aggressive subset of squamous cell carcinoma, which is characterized by the translocation of nuclear protein in testis (NUT) gene that is mostly fused with bromodomain and extraterminal (BET) family proteins, such as BRD3 and BRD4 [1], generating BRD3-NUT and BRD4-NUT, respectively. A non-BET member, nuclear receptor binding SET domain 3 (NSD3), was also seen to be fused with $N U T$ (NSD3-NUT) [2,3], but this seems to be less

\footnotetext{
* Correspondence: leandrojco1986@gmail.com

${ }^{1}$ Centro de Oncologia, Hospital Sírio Libanês, Rua Dona Adma Jafet, 91. 2nd floor. Building A, São Paulo 01308-050, Brazil

Full list of author information is available at the end of the article
}

frequent than BRD3-NUT and BRD4-NUT. The majority of the cases occur in the head, neck, and mediastinum, although there are reports involving the bladder, pancreas, adrenal gland, kidney, and salivary gland [4]. NMC differs from other carcinomas, which usually have complex karyotypes, because it is characterized by a few or a single translocation, most often the BRD4-NUT: $\mathrm{t}(15 ; 19)(\mathrm{q} 14 ; \mathrm{p} 13.1)$ [4].

Until 2011, NMC was considered an extremely rare carcinoma, with only 28 reported cases worldwide [5]. Since 2012, the number of diagnosed cases increased enormously; this was identified in a review in the International NUT Midline Carcinoma Registry, which detected 48 cases of NMC from 2011 to 2014, of which

(c) The Author(s). 2019 Open Access This article is distributed under the terms of the Creative Commons Attribution 4.0 International License (http://creativecommons.org/licenses/by/4.0/), which permits unrestricted use, distribution, and 
86\% were BRD4-NUT positive [6]. This review suggests that NMC is probably underdiagnosed.

We describe here the first Brazilian case of NMC with BRD4-NUT fusion detected in next-generation sequencing (NGS) panel and we present the clinical evolution of this patient. Until recently, to the best of our knowledge, no cases of NMC had been reported in Latin America [4, 7]. Salles et al. described four patients with typical NMC histopathology and NUT positivity in the nucleus [8]. However, the fusion was not molecularly described. Since there is a clear failure in detecting $\mathrm{NMC}$ in patients, and further studies are required to provide better chances for these patients, we understand that there is a need to report and better characterize cases of NMC.

\section{Case presentation}

A 42-year-old Caucasian man presented in December 2016 with productive cough, facial pain, and rhinorrhea. $\mathrm{He}$ is an engineer, who does not smoke tobacco, and he had no significant premorbid conditions. There was no history of prescription drug use, and no significant family history. Neurological, cardiovascular, respiratory, and abdominal examinations were normal, except for tenderness of the face elicited by palpation. He was first diagnosed as having acute rhinosinusitis and treated with antibiotics (details were not available), without improvement. Due to symptoms persistence, magnetic resonance imaging (MRI) of his face was ordered. This study revealed an expansive irregular heterogeneous lesion $(4.5 \times 3.5 \times 4.0 \mathrm{~cm})$, with its central portion located on the interface between the left maxillary sinus and the pterygopalatine fossa. This lesion invaded medially the nasal cavity and posterosuperiorly the left orbit apex with an intracranial extension through the inferior orbital fissure (Fig. 1a-d). There was no lymphadenopathy and no perineural invasion. A biopsy demonstrated poorly differentiated squamous cell carcinoma with negative in situ hybridization for Epstein-Barr encoding region (EBER). Human papillomavirus (HPV) genotyping test was negative as well. Positron emission tomography-computed tomography (PET-CT) was negative for nodal and systemic metastases. His total leukocyte and platelet counts, as well as hemoglobin levels, were all within normal limits. His biochemical parameters, including serum electrolytes, renal function test, and liver function test, were also normal.

He received, from January 2017 to April 2017, induction therapy with docetaxel $75 \mathrm{mg} / \mathrm{m}^{2}$ at day 1 , cisplatin $100 \mathrm{mg} / \mathrm{m}^{2}$ at day 1 , and fluorouracil (5-FU) $1000 \mathrm{mg} / \mathrm{m}^{2}$ per day at day 1 to day 4 (DCF) for six cycles every 3 weeks, with clinical benefit and stable disease by MRI and PET-CT (Figs. 1 and 2). Chemoradiotherapy (radiotherapy 35 fractions - 70 Gy) with weekly systemic chemotherapy based on carboplatin 1.5 area under the curve (AUC), paclitaxel $45 \mathrm{mg} / \mathrm{m}^{2}$, and cetuximab 400 $\mathrm{mg} / \mathrm{m}^{2}$ was administered for 7 weeks from May 2017 to July 2017. Concurrently, weekly intra-arterial chemotherapy with cisplatin $150 \mathrm{mg} / \mathrm{m}^{2}$ was performed for 5 weeks with grade 2 myelotoxicity and nausea.

New imaging evaluation, 1 month after the end of the last treatment, revealed a good partial response in the primary lesion (Figs. 1e-h and 2). However, PET-CT showed multiple suspicious lesions in his bones and lungs (Fig. 3), which were histologically confirmed (Fig. 4a, b).
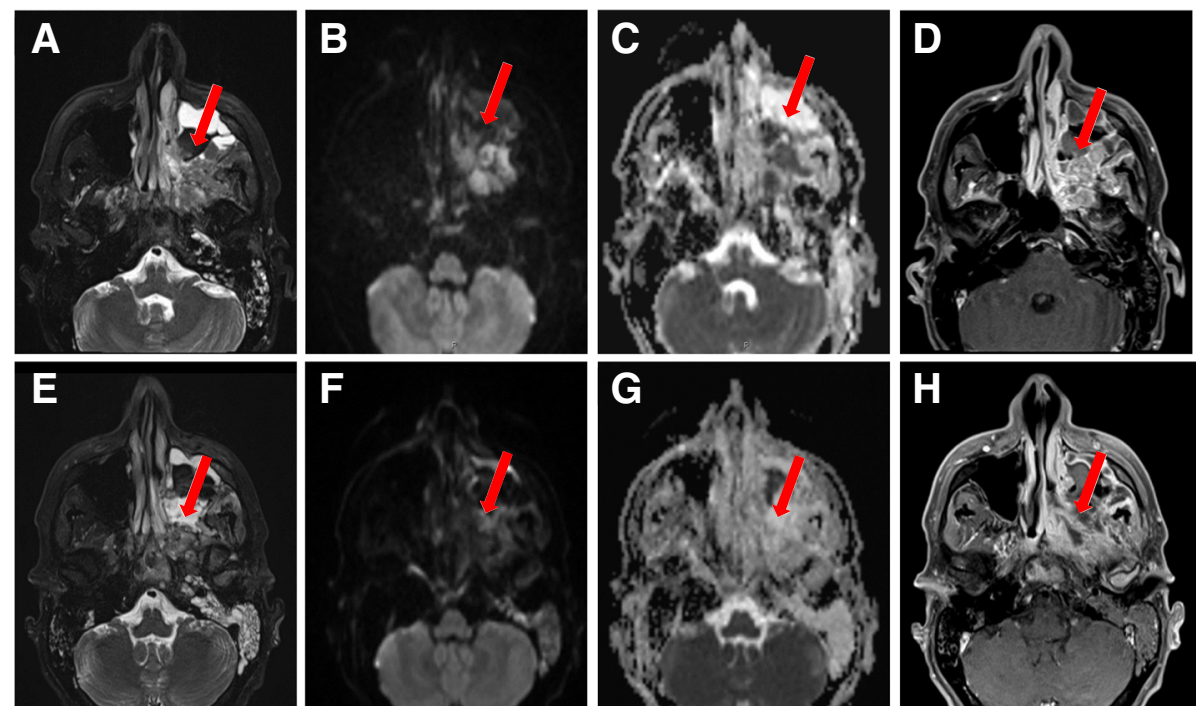

Fig. 1 Local tumor response seen in head and neck magnetic resonance images. Magnetic resonance images from baseline before second-line chemotherapy (a-d) showing locally advanced left maxillary sinus mass (arrows), infiltrating adjacent sinuses and skull base foramina. Follow-up magnetic resonance images (e-h) showing significant tumor shrinkage (arrows) with areas of necrosis, representing local morphological partial response 

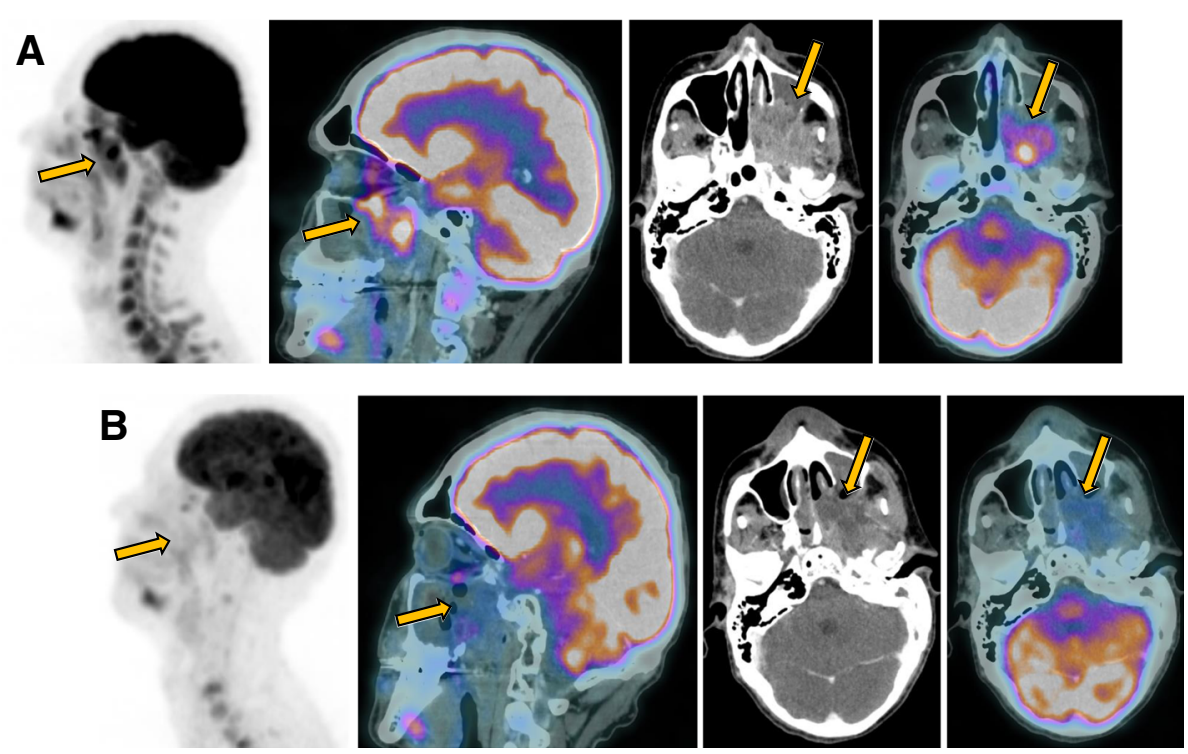

Fig. 2 Local complete metabolic response seen in ${ }^{18} \mathrm{~F}$-fluorodeoxyglucose positron emission tomography-computed tomography. Fluorodeoxyglucose-positron emission tomography-computed tomography head and neck images from baseline before second-line chemotherapy (a) showing locally advanced left maxillary sinus enhanced mass (arrows) with fluorodeoxyglucose avidity. Positron emission tomography-computed tomography of 1 month after end of treatment (b) confirming morphological shrinkage of the left maxillary sinus with extensive necrosis (arrows) without any fluorodeoxyglucose uptake, representing local complete metabolic response

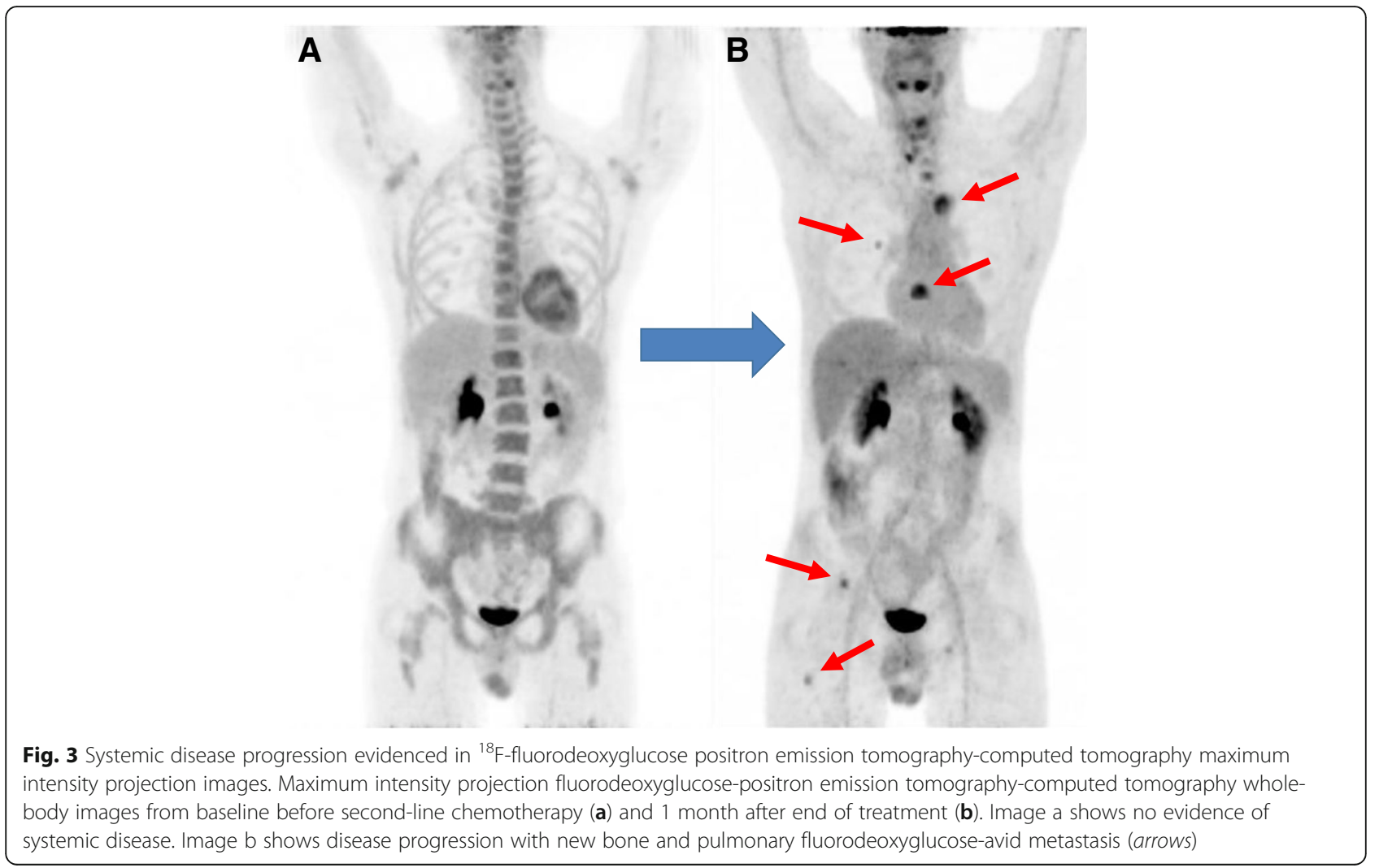



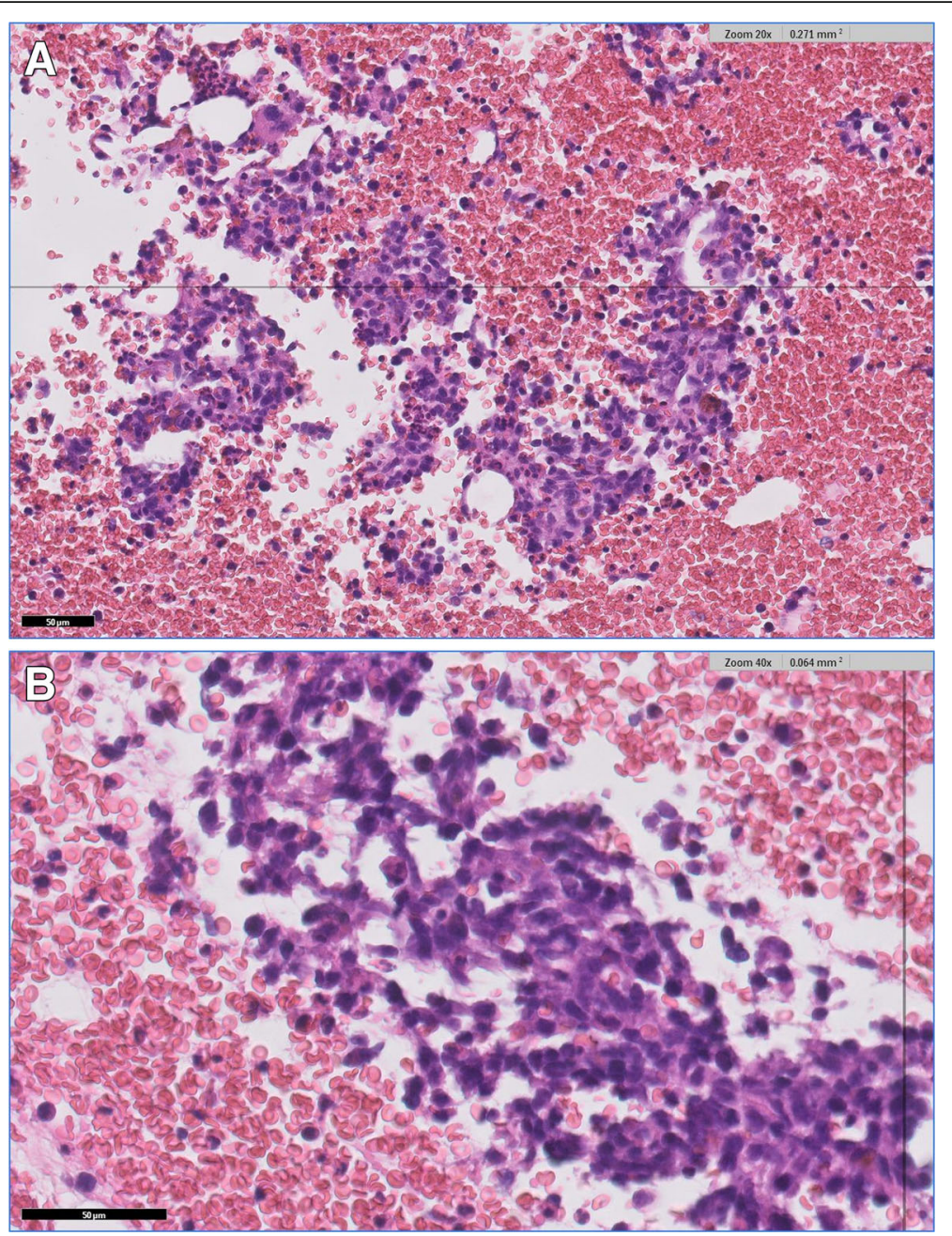

Fig. 4 a Bone metastasis of poorly differentiated carcinoma showing neoplastic epithelioid clusters with small cells (hematoxylin and eosin, $\times 200$ ). $\mathbf{b}$ Higher magnification of the neoplastic clusters (hematoxylin and eosin, $\times 400$ )

Programmed death-ligand 1 (PD-L1) expression by immunohistochemistry (IHC) was negative (SP263 Ventana). In order to look for other therapeutic possibilities, a formalinfixed paraffin-embedded (FFPE) tumor biopsy was sent to the Foundation Medicine with patient consent. Deoxyribonucleic acid (DNA) extracted from FFPE and hybrid capture-based NGS was applied to perform the FoundationOne $^{\text {tx }}$ test, which comprises a panel of 315 genes known to carry somatic mutations in human solid tumors, as well as introns of 28 genes involved in rearrangements. The test showed a rearrangement of BRD4NUT characterizing NMC. No other mutations were found; microsatellite stability and low mutational burden were reported. The IHC for NUT protein was performed and stained positively in neoplastic nuclei (Fig. 5).

Due to the lack of available clinical trials in the country for this highly aggressive tumor, our patient received two more cycles of chemotherapy, but, unfortunately, without any response. He died exactly 2 months after metastatic disease was diagnosed.

\section{Discussion}

We describe the first report of a molecular characterized BRD4-NUT carcinoma in Brazil and Latin America. Our patient showed a significant partial response in the primary lesion but progressed with multiple metastatic lesions in bone and lungs.

Reports of NMC have been increasing since it was originally described as a genetically defined entity in 2004 [9]. It can affect individuals of all ages, despite the initial thought that it only affected children and young adults. The median age of diagnosis is 24 years. The most common primary sites are thorax, in $50 \%$ of the patients, and head and neck, in 39\% of patients. There are other primary sites (non-midline, non-thoracic, or head and 


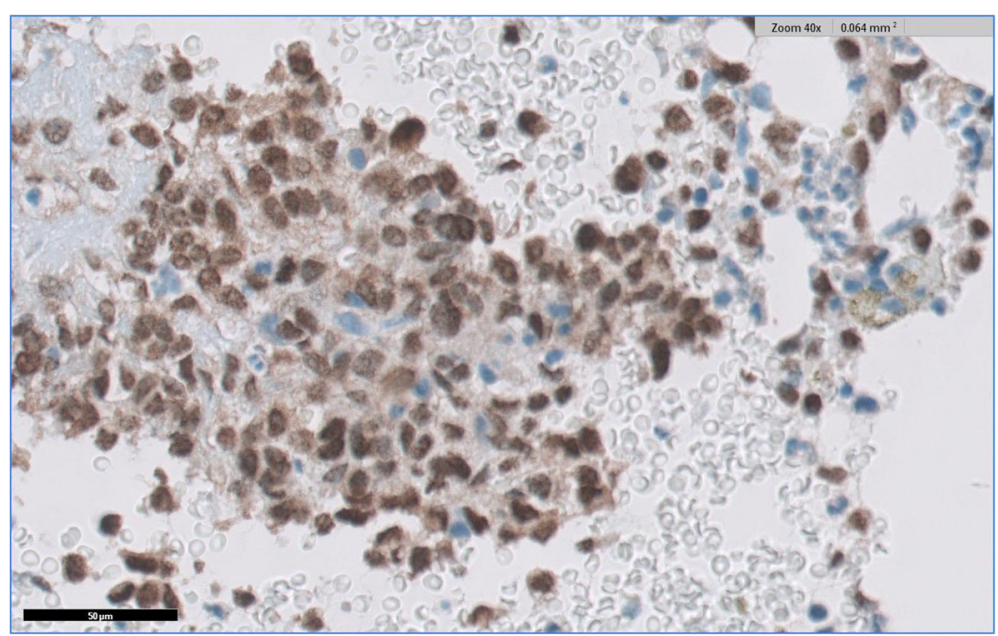

Fig. 5 NUT immunohistochemistry staining positively in neoplastic nuclei

neck) described in reports of NMCs, such as soft tissue or bone, which can account for $11 \%$ of all cases [10]. In Brazil, lung and head and neck cancers are among the ten most frequent cancers, especially in men [11]. However, until now, there were no cases of NUT-BRD4 NMC confirmed in Brazil, probably due to underdiagnosis.

NMC is usually very aggressive. Not rarely, it is metastatic at diagnosis and has poor survival rates. An analysis of a clinical database with 63 patients with NMC and outcome data of 54 patients showed a median overall survival (OS) of 6.7 months. The 2-year OS was 19\% [12]. A systematic review and individual patient data analysis of 119 cases showed median OS of only 5 months. Radiotherapy and chemotherapy had a significant impact on OS, while surgery, BET inhibitors, and histone deacetylase inhibitors (HDACi) did not affect survival significantly [13].

As previously discussed, the karyotypes of NMC are not complex; they frequently have a clonal translocation of the NUTM1 gene, classically $\mathrm{t}(15 ; 19)(\mathrm{q} 14 ; \mathrm{p} 13.1)$, which places NUT in the frame with BRD4. This feature differs from other carcinomas because the latter develop over years due to an accumulation of mutations and genetic aberrations [14]. The BRD4-NUT fusion oncoproteins drive a series of disruptions of gene expression through chromatin remodeling [15], overexpression of MYC [16], and sequestration of the activated form of p53 [17]. Another possibility is the fusion of NUT with BRD3 or NSD3, which are functionally related to BRD4. Therefore, recruitment of NUT to the chromatin through the BET family proteins is probably necessary for the oncogenesis of NMC [17].

On histological examination, NMC can have a broad morphologic range, in many cases resembling squamous cell carcinoma, in others showing small undifferentiated cells with or without areas of abrupt keratinization. Therefore, diagnosis should not be assumed just based on histological aspect [18].

The definitive diagnosis must be by demonstration of the NUTM1 rearrangement. There is no consensus on which pathology material of the patient should be submitted to molecular tests. Some authors suggested performing IHC or molecular tests in all poorly differentiated non-cutaneous carcinomas, with or without squamous differentiation, with a monomorphic appearance. Glandular tumors do not need to be tested. Viral etiology, such as HPV or Epstein-Barr virus (EBV), is not associated with $\mathrm{NMC}$ and can be used to rule this diagnosis out. However, NMC can be strongly positive for p16, despite its negativity for HPV; therefore, it should not be used for excluding NMC [14].

IHC staining of greater than $50 \%$ of tumor nuclei on FFPE tissue using the monoclonal rabbit antibody to NUT (clone C52B1) has a specificity of $100 \%$, and sensitivity of $87 \%$ for the diagnosis of NMC. Some germ cells tumors can also stain, but usually focally $(<10 \%)$ [19]. Confirmatory molecular tests are not mandatory. However, they can be used if the C52B1 antibody is not available or to identify the fusion partner to NUT, which may have clinical and prognostic relevance. For example, NSD3 or BRD3-NUT-positive NMC was associated with a better OS than those with BRD4-NUT, especially in non-thoracic NMC [14]. The assays that can be used for this purpose are fluorescence in situ hybridization (FISH), reverse transcriptase-polymerase chain reaction (RT-PCR), cytogenetics, and NGS-based approaches. Molecular diagnostic methods have limitations, such as the cost and access to quality services [14].

Currently, there is no standard of care for treatment of NMC. Incomplete or no surgical resection and no initial radiotherapy have been associated with shorter progression- 
Table 1 NUT midline carcinoma clinical trials available at Clinicaltrials.gov

\begin{tabular}{|c|c|c|c|c|}
\hline Trial & Type of study/ population & Regimen & Mechanism of action & Status \\
\hline NCT01587703 & $\begin{array}{l}\text { Phase } \mathrm{I} / \mathrm{II} \text { - Diagnosis of NMC determined by } \mathrm{IHC} \text { and/or } \\
\text { detection of NUT gene translocation by FISH, treatment } \\
\text { naïve or with prior therapy }\end{array}$ & GSK525762 & BET protein inhibitor & Active, not recruiting \\
\hline NCT03702036 & $\begin{array}{l}\text { Compassionate use - Diagnosis of NMC determined by } \\
\text { IHC and/or detection of NUT gene translocation by FISH, } \\
\text { with no other satisfactory alternative treatment }\end{array}$ & $\begin{array}{l}\text { GSK525762 } \\
\text { (molibresib) }\end{array}$ & $\begin{array}{l}\text { Inhibitor of the binding } \\
\text { of BET proteins to } \\
\text { acetylated histones }\end{array}$ & Available \\
\hline NCT02307240 & $\begin{array}{l}\text { Phase I - Diagnosis of an advanced solid tumor such as } \\
\text { breast cancer or NMC, that has progressed despite } \\
\text { standard therapy, or for which no standard therapy exists }\end{array}$ & CUDC-907 & $\begin{array}{l}\mathrm{HDAC} \text { and } \mathrm{PI} 3 \mathrm{~K} \\
\text { Inhibitor }\end{array}$ & Active, not recruiting \\
\hline NCT02698176 & $\begin{array}{l}\text { Phase IB - Diagnosis of one of the following advanced } \\
\text { solid tumors for which standard therapy either does not } \\
\text { exist or has proven ineffective, intolerable, or } \\
\text { inacceptable for the participant: NMC;TNBC; NSCLC; or } \\
\text { CRPC }\end{array}$ & MK-8628 & BET protein inhibitor & Terminated due to limited efficacy \\
\hline NCT02516553 & $\begin{array}{l}\text { Phase I - Diagnosis of advanced unresectable and/or } \\
\text { metastatic solid tumor, refractory to conventional } \\
\text { treatment or for whom no therapy of proven efficacy } \\
\text { exists, or who are not amenable to standard therapies. } \\
\text { Part Ib includes patients with SCLC, CRPC, CRC or NMC }\end{array}$ & Bl 894999 & BET protein inhibitor & Recruiting \\
\hline NCT02259114 & $\begin{array}{l}\text { Phase I - Advanced or metastatic: TNBC, NSCLC, CRPC, } \\
\text { pancreatic ductal adenocarcinoma, NMC, for which } \\
\text { standard therapy either does not exist or has proven } \\
\text { ineffective, intolerable or inacceptable for the patient }\end{array}$ & $\begin{array}{l}\text { OTX015/ } \\
\text { MK-8628 } \\
\text { (birabresib) }\end{array}$ & BET protein inhibitor & $\begin{array}{l}3 / 10 \text { patients with NMC with PR } \\
\text { with duration of } 1.4 \text { to } 8.4 \text { months }\end{array}$ \\
\hline NCT02711137 & $\begin{array}{l}\text { Phase } 1 / 2 \text { - Histologically or cytologically confirmed } \\
\text { diagnosis of relapsed or refractory advanced or } \\
\text { metastatic malignancies (solid or hematologic) }\end{array}$ & INCB057643 & BET protein inhibitor & Terminated due to safety issues \\
\hline NCT02431260 & $\begin{array}{l}\text { Phase } 1 / 2 \text { - Any advanced solid tumor or lymphoma; } \\
\text { acute leukemia, myelodysplastic syndrome, } \\
\text { myelodysplastic /myeloproliferative neoplasms, } \\
\text { myelofibrosis, and multiple myeloma }\end{array}$ & INCB054329 & BET protein inhibitor & $\begin{array}{l}\text { Terminated by the sponsor due to } \\
\text { pharmacokinetics variability [20] }\end{array}$ \\
\hline NCT02369029 & $\begin{array}{l}\text { Phase } 1 \text { - Patients with advanced tumors refractory to } \\
\text { any standard treatment, with no standard therapy } \\
\text { available or in whom standard therapy is not a } \\
\text { therapeutic option }\end{array}$ & BAY1238097 & BET protein inhibitor & $\begin{array}{l}\text { Terminated because of dose- } \\
\text { limiting toxicities at a dose below } \\
\text { targeted drug exposure [21] }\end{array}$ \\
\hline
\end{tabular}

BET bromodomain and extraterminal, CRPC castration-resistant prostate cancer, CRC colorectal cancer, FISH fluorescence in situ hybridization, $H D A C$ histone deacetylase, IHC immunohistochemistry, NMC NUT midline carcinoma, NSCLC non-small cell lung cancer, PI3K phosphoinositide 3-kinase, PR partial response, SCLC small cell lung cancer, TNBC triple negative breast cancer

free survival and OS. However, no chemotherapeutic regimen has been associated with better outcomes [12].

Targeted therapies are in development encompassing different strategies (Table 1). A first-in-class BET inhibitor, birabresib, a selective inhibitor of BRD2, BRD3, and BRD4 was evaluated in a recently published phase Ib trial. In this trial with 43 patients, 10 of them with NMC, partial response was observed in 3 out of these 10 patients with NMC.

In addition, other targets have been studied. A dual histone deacetylases (HDAC) and phosphoinositide 3kinases (PI3K) inhibitor, CUDC-907, was tested in a preclinical trial and showed some positive results. The rational was that inhibition of HDAC and PI3K, upstream regulators of $\mathrm{MYC}$, could reduce $\mathrm{MYC}$ protein levels, a key oncogenic target in NMC, and ultimately lead to growth suppression and cell death [22]. Activity of these drugs in NMC was shown in vivo and in vitro, associated with decreased MYC protein levels. This activity should be further studied in clinical studies.
This is the first Brazilian case of NMC with BRD4NUT fusion. Because of this diagnosis, the routine in our Pathology department has changed and the IHC for NUT protein is now validated and performed in all cases of poorly differentiated carcinomas, with or without keratinization, especially those occurring in young patients, never smokers, with unusual IHC patterns, atypical morphology and/or occurring in midline sites.

\section{Conclusion}

Our case is the first Brazilian case of NMC with BRD4NUT fusion detected in a NGS panel. The diagnosis of NMC holds importance for prognostic value as well as for clinical trials with targeted therapy. This report reinforces the need for definitive diagnosis of this subtype of low differentiated carcinoma, and highlights the IHC evaluation, the most available and accessible method, as an important diagnostic tool. 


\section{Acknowledgements}

No funding received.

\section{Authors' contributions}

LCO, ABLG, MTL, MTA, and LAT described the case and wrote the initial article. OF was the patient's personal doctor and was a reviewer of the article, together with JVAMG. FGB analyzed, selected, and wrote the subtitles for the images. All authors read and approved the final manuscript.

\section{Funding}

Not applicable.

\section{Availability of data and materials}

Not applicable.

\section{Ethics approval and consent to participate}

Not applicable.

\section{Consent for publication}

Written informed consent was obtained from the patient's next of kin for publication of this case report and any accompanying images. A copy of the written consent is available for review by the Editor-in-Chief of this journal.

\section{Competing interests}

The authors declare that they have no competing interests.

\section{Author details}

'Centro de Oncologia, Hospital Sírio Libanês, Rua Dona Adma Jafet, 91. 2nd floor. Building A, São Paulo 01308-050, Brazil. '2 Instituto de Ensino e Pesquisa, Hospital Sírio Libanês, São Paulo, Brazil. ${ }^{3}$ Serviço de Medicina Nuclear, Hospital Sírio Libanês, São Paulo, Brazil. ${ }^{4}$ Serviço de Oncologia, Instituto do Câncer do Estado de São Paulo, Universidade de São Paulo, São Paulo, Brazil. ${ }^{5}$ Serviço de Anatomia Patológica, Hospital Sírio Libanês, São Paulo, Brazil.

Received: 26 March 2019 Accepted: 30 July 2019

Published online: 07 September 2019

\section{References}

1. French C. NUT midline carcinoma. Nat Rev Cancer. 2014;14(3):149-50.

2. French CA, et al. NSD3-NUT fusion oncoprotein in NUT midline carcinoma: implications for a novel oncogenic mechanism. Cancer Discov. 2014;4(8):928-41.

3. Suzuki S, et al. NSD3-NUT-expressing midline carcinoma of the lung: first characterization of primary cancer tissue. Pathol Res Pract. 2015;211(5):404-8.

4. French CA. Pathogenesis of NUT midline carcinoma. Annu Rev Pathol. 2012 7:247-65.

5. Stelow EB. A review of NUT midline carcinoma. Head Neck Pathol. 2011:5(1):31-5.

6. Chau NG, et al. Intensive treatment and survival outcomes in NUT midline carcinoma of the head and neck. Cancer. 2016:122(23):3632-40.

7. French CA. The importance of diagnosing NUT midline carcinoma. Head Neck Pathol. 2013;7(1):11-6.

8. Salles PG, et al. Expression of P16 in NUT carcinomas with no association with human papillomavirus (HPV). Appl Immunohistochem Mol Morphol. 2014;22(4):262-5.

9. French CA, Kutok JL, Faquin WC, et al. Midline carcinoma of children and young adults with NUT rearrangement. J Clin Oncol. 2004;22:4135-9.

10. Chau NG, Ma C, Danga K, et al. A novel prognostic risk classification model for NUT midline carcinoma: A largest cohort analysis from the NMC registry. J Clin Oncol. 2018;36(suppl):6085.

11. Ministério da Saude, Instituto Nacional de Câncer José Alencar Gomes da Silva. Estimate/2018 - Cancer Incidence in Brazil (Rio de Janeiro), 2017. ISBN 978-85-7318-361-0.

12. Bauer DE, et al. Clinicopathologic features and long-term outcomes of NUT midline carcinoma. Clin Cancer Res. 2012;18(20):5773-9.

13. Giridhar P, Mallick S, Kashyap L, Rath GK. Patterns of care and impact of prognostic factors in the outcome of NUT midline carcinoma: a systematic review and individual patient data analysis of 119 cases. Eur Arch Otorhinolaryngol. 2018;275(3):815-21.

14. French CA. NUT Carcinoma: Clinicopathologic features, pathogenesis, and treatment. Pathol Int. 2018;68(11):583-95.
15. Alekseyenko AA, Walsh EM, Wang $X$, et al. The oncogenic BRD4-NUT chromatin regulator drives aberrant transcription within large topological domains. Genes Dev. 2015;29:1507-23.

16. Grayson AR, Walsh EM, Cameron MJ, et al. MYC, a downstream target of BRD-NUT, is necessary and sufficient for the blockade of differentiation in NUT midline carcinoma. Oncogene. 2014;33:1736-42.

17. Reynoird N, Schwartz BE, Delvecchio M, et al. Oncogenesis by sequestration of CBP/p300 in transcriptionally inactive hyperacetylated chromatin domains. EMBOJ. 2010:29:2943-52.

18. Evans AG, French CA, Cameron MJ, et al. Pathologic characteristics of NUT midline carcinoma arising in the mediastinum. Am J Surg Pathol. 2012:36:1222-7.

19. Haack H, Johnson LA, Fry CJ, et al. Diagnosis of NUT midline carcinoma using a NUT-specific monoclonal antibody. Am J Surg Pathol. 2009:33:984-91.

20. Lewin J, Soria JC, Stathis A, et al. Phase Ib trial with birabresib, a small molecule inhibitor of bromodomain and extraterminal proteins, in patients with selected advanced solid tumors. J Clin Oncol. 2018;36(30):3007-14.

21. Postel-Vinay S, Herbschleb K, Massard C, et al. First-in-human phase I dose escalation study of the Bromodomain and Extra-Terminal motif (BET) inhibitor BAY 1238097 in subjects with advanced malignancies. Eur J Cancer. 2016;69:S7-8.

22. Sun K, Atoyan R, Borek MA, et al. Dual HDAC and PI3K inhibitor CUDC-907 downregulates MYC and suppresses growth of MYC-dependent cancers. Mol Cancer Ther. 2017;16(2):285-99.

\section{Publisher's Note}

Springer Nature remains neutral with regard to jurisdictional claims in published maps and institutional affiliations.
Ready to submit your research? Choose BMC and benefit from:

- fast, convenient online submission

- thorough peer review by experienced researchers in your field

- rapid publication on acceptance

- support for research data, including large and complex data types

- gold Open Access which fosters wider collaboration and increased citations

- maximum visibility for your research: over $100 \mathrm{M}$ website views per year

At $\mathrm{BMC}$, research is always in progress.

Learn more biomedcentral.com/submissions 